\title{
㩆 '¿Usted no me saluda porque debe?'. Vecindad, moralidad y política en Cooperativa Las Cuatro Banderas (Córdoba)
}

RMA

Antropología Social
Ivana Bartolozzi*

Silvia Ayelén Koopmann*

*Maestría en Antropología. Facultad de Filosofía y Humanidades. Universidad Nacional de Córdoba. E-mail: ivana_bartolozzi@hotmail.com /

sakoopmann@gmail.com

\section{Resumen}

Los regímenes morales que ordenan y regulan la vida de los sujetos han sido materia de análisis por parte de la Antropología, como así también los diversos conflictos, antagonismos y negociaciones que estos sistemas normativos suscitan en determinados conjuntos sociales. En este sentido, la necesidad de indagar sobre los procesos sociales que otorgan contenido ético a determinados conceptos, requiere de estudios que, etnográficamente, puedan dar cuenta acerca de cómo se construyen y disputan determinadas valoraciones en cada contexto particular. En el presente artículo, exponemos las formas como son categorizados los vecinos de Cooperativa Las Cuatro Banderas por parte de los miembros de la Comisión Directiva, de acuerdo al pago (o no) del terreno, como así también, las repercusiones que esto conlleva hacia otras dimensiones de la vida social. Al mismo tiempo, los discursos y prácticas de quienes presiden la entidad, también son interpeladas por aquellos que, desde afuera, juzgan las formas -individuales o colectivas- de hacer política. Esto nos permitirá ver cómo se motorizan estas distinciones morales en un proceso liminal ante la posible disolución de la cooperativa a partir de la escrituración individual de los lotes, en el marco de un programa provincial de regularización de viviendas sociales.

Palabras clave: Moralidad; Vecinos; Cooperativa; Terreno; Prácticas Políticas.

'¿You don't say hello anymore because you are in debt?' Neighbors, morality and politics in Cooperative Las Cuatro Banderas (Córdoba city)

\begin{abstract}
The moral regime that manage and regulate the life of the individuals have been subject of analysis of Anthropology, as well as the diverse conflicts, antagonisms, and negotiations that these normative systems provoke in certain social groups. Therefore, the need to investigate the social processes that grant ethical content to certain concepts and practices requires of a study that, from an ethnographical approach, would explain how some specific judgments are made and challenged in each single context. This article exposes the different ways in which the neighbors of the Cooperative "Las Cuatro Banderas" are categorized by the members of the executive committee, according to the payment (or nonpayment) of the land, and the consequences carried to other dimensions of their social life as a result of such categories. At the same time, the speeches and practices of those who preside the committee, are also addressed by those outside the entity, who judge the forms - individual or collective-of doing politics. Understanding this will allow us to see how these moral distinctions are set in motion within a liminality process when facing the possible dissolution of the cooperative, once finished the individual public deed of the land within a social housing state program.
\end{abstract}

Keywords: Morality; Neighbors; Cooperative; Land; Politic practices.

En este artículo ${ }^{1}$ nos proponemos analizar los modos como son nombrados y valorados los vecinos de Cooperativa Las Cuatro Banderas², a partir de las

\footnotetext{
1 Este artículo forma parte de nuestro trabajo de tesis para obtener la licenciatura en Comunicación Social (ECI-UNC), denominado "A las flores se las llevaron otros. Una etnografía sobre los sentidos de 'lo barrial' y las prácticas políticas en Cooperativa Las Cuatro Banderas, a través de la imagen fotográfica", dirigida por la Dra. Natalia Bermúdez.

2 Los nombres propios, tanto de personas como de lugares, han sido modificados a fin de resguardar la privacidad e intimidad de las personas que colaboraron con este trabajo.
}

consideraciones morales $^{3}$ que hacen las mujeres 3 Siguiendo a Balbi (2007), el análisis de los fundamentos morales a
partir de los cuales las personas clasifican, evalúan y llevan adelante
sus acciones debe centrarse fundamentalmente en las relaciones y
procesos sociales de los cuales ellos dependen, evitando asumirlos
como "sistemas abstractos, 'culturales', que existen per se, ya como
emanaciones más o menos mecánicas, de la 'sociedad', la 'estructura
social' o el 'sistema social'" (2007:62); o bien como 'ideología',
'lenguaje simbólico' o 'recursos retórico', que esconde o enmascara
las motivaciones maximizadoras según las cuales las invocaciones a
normas y valores deben ser explicados en función de sus intereses.
En este marco, coincidimos con el autor en tanto sostiene que "me 
miembros de la Comisión Directiva, como así también las tensiones que producen entre ellas los alcances y límites de sus propias funciones. En efecto, la administración del pago de los terrenos genera una serie de intercambios ambiguos en el cruce entre los lazos vecinales y jurídicos, en donde los vecinos, en tanto socios, son enjuiciados moralmente de acuerdo al cumplimiento o no de dichas cuotas. Al mismo tiempo, son las propias funcionarias quienes se atribuyen acusaciones y complicidades a la hora de determinar sus roles y la forma 'correcta' en que deben realizarlos. Las fronteras entre lo público y lo privado, se vuelven difusas y complejizan las relaciones entre funcionarias y socios, tornando porosos los límites de dicha vinculación.

Estas fricciones nos permitirán ver que los valores que están siendo disputados se enmarcan en un universo de sentido donde las acciones políticas se evalúan en función de los logros 4 alcanzados por cada Comisión Directiva desde la conformación de la cooperativa, y a la forma en que se consiguen, esto es, de manera individual o apelando a una acción conjunta ${ }^{5}$. Como veremos, ambas representaciones se debaten a partir de cierto recorrido histórico donde los primeros habitantes -miembros de las primeras Comisiones Directivassostienen distinciones con quienes ocuparon esos cargos después, atribuyéndose una forma de trabajo colectiva y solidaria, opuesta a las gestiones actuales.

A mediados de nuestro trabajo de campo, el gobierno provincial anunció el lanzamiento del Programa de Regularización y Escrituración de Viviendas Sociales ${ }^{6}$ en el que Cooperativa Las Cuatro Banderas fue incluida como beneficiaria. Esto significó una actualización de

parece imprescindible referir los valores morales a instituciones, entramados de relaciones sociales y procesos sociales específicos en función de los cuales habrá que intentar dar cuenta tanto de sus propiedades formales como de sus contenidos" (2007:68). Por ello, Balbi advierte sobre el carácter dinámico y polisémico de los valores (en tanto involucrados en la experiencia humana siempre heterogénea y dinámica), para concluir que "no sólo los valores morales pueden ser investidos de diversos sentidos en el curso de la vida social, sino que el propio carácter 'moral' de los 'valores morales' es producto de los mismos procesos de producción de sentidos y debe, por ende, ser explicado etnográficamente" (2007:81).

${ }^{4}$ La letra cursiva será utilizada para referirse a expresiones textuales de los informantes, mientras que las comillas dobles corresponderán a citas teóricas. Las comillas simples se utilizarán para resaltar expresiones relevantes o relativizar su uso.

${ }^{5}$ Los logros más importantes giran alrededor del tendido de luz eléctrica y la red de agua potable. Quiénes lo consiguieron o quiénes se movieron más, son algunas de las manifestaciones a partir de las cuales los vecinos distinguen modos y protagonismos.

6 El programa consiste en la gestión y entrega de escrituras individuales a loteos y asentamientos particulares, como así también a beneficiarios de planes o programas de vivienda social, como parte de una política "de carácter social. destinada primordialmente a aquellas personas o familias que se encuentran en una situación económico social vulnerable" con el objetivo de "remediar la situación dominial" (Boletín Oficial del Gobierno de la Provincia de Córdoba. Año XCVII - Tomo DXXXII N 92). Más información en: http://www.cba.gov.ar/ vercanal.jsp?idCanal $=63465$ viejas disputas en torno a cómo debería ser la vinculación con el gobierno, como así también aceleró y multiplicó los juicios morales en vistas a la necesidad de pago de los terrenos para acceder a la escritura individual. Este período se convirtió así en un momento fértil para recoger y analizar los diversos sentidos de propiedad que los vecinos contraponían a los hegemónicamente instalados a través de dicho programa, y las diferentes representaciones acerca de "lo barrial" (Gravano 2003) que rondaban las discusiones más importantes sobre el presente y el futuro de la cooperativa.

\section{Sobre la Cooperativa}

Cooperativa Las Cuatro Banderas está ubicada en el borde sur del ejido urbano de la ciudad de Córdoba. Se trata de una extensión de terreno de unos 300 m2 que limita con barrio Villa Emancipación, uno de los más poblados de la ciudad ${ }^{8}$. Alrededor del año 1994 un grupo de personas comenzó a usurpar poco a poco estas tierras hasta conformar un asentamiento de cerca de 50 familias provenientes de diversos sectores, principalmente familiares o allegados a habitantes de barrios vecinos. Según el relato de los primeros en llegar $^{9}$, se trataba de un área descampada, irregular, llena de huecos y mallines, por lo que el trabajo de relleno se reitera en los discursos de los protagonistas como muestra del esfuerzo empeñado en la tarea de construir un espacio habitable. Acá no había nada o estas tierras no servían son algunas de las expresiones a partir de las cuales los vecinos extienden la distancia material y simbólica entre aquel lugar y el paisaje actual de la cooperativa, motivo de orgullo para muchos ${ }^{10}$.

\footnotetext{
${ }^{7}$ Si bien este tema no será desarrollado aquí, entendemos necesario mencionarlo no sólo porque guardó una centralidad nodal en nuestra investigación, sino también porque abre una serie de discusiones sumamente ricas en torno a los modos como se construyen y disputan sentidos en la definición y apropiación de los espacios habitados (Bermúdez y Previtali 2013).

${ }^{8}$ Villa Emancipación se ubica a unos diez kilómetros del centro de la ciudad, hacia el suroeste. Sus orígenes datan de los años 30, cuando su primer propietario promocionó y vendió las tierras, la mayoría de ellas convertidas en quintas familiares. Cerca de los años 50, el establecimiento de fábricas ligadas a la industria automotriz -particularmente de las Industrias Káiser Argentina- fue trascendental, no sólo porque significó un incremento notable de la población (hoy alcanza los 40 mil habitantes), sino porque contribuyó a que este sector sea asociado a un barrio típicamente obrero y popular. A mediados de la década del 80 , y más aún en los 90 , el porcentaje de población migrante (especialmente boliviana) fue cada vez mayor, lo cual fue determinante para la conformación de Las Cuatro Banderas.

9 La forma en que se fue poblando este sector fue relatada de diversas maneras de acuerdo a cada informante. Algunos se atribuían cierta amistad con el 'guardia' del predio, lo cual facilitó el ingreso, mientras que otros desconocen tal versión, refiriéndose más bien a una situación azarosa donde la oportunidad de desmontar y hacerse algo aparece como la principal razón para la ocupación de estos lotes en desuso.

10 La principal diferencia que establecen los vecinos se da en función de las construcciones de las casas. Las primeras viviendas estaban hechas en madera por lo que, según los relatos, el lugar era nombrado informalmente como "Las tablitas". La edificación actual de material
} 
La tramitación de la compra de los terrenos también constituye otro de los puntos nucleares que hilvanan los relatos acerca de cómo ellos se convirtieron en un ejemplo para los demás barrios de Córdoba. El interés y la movilización por contactar a los dueños, como así también la predisposición para adquirirla 'legalmente', son cartas que se exponen a la hora de distinguirse de otros asentamientos, principalmente las villas o de quienes reciben cosas de arriba, como los beneficiarios de planes de vivienda. La empresa propietaria acordó la entrega de los lotes si los vecinos se agrupaban bajo una cooperativa ${ }^{11}$. Así, en el año 1996, el Instituto Nacional de Cooperativas y Mutuales (INACyM, hoy INAES) decretó formalmente la conformación de Cooperativa Las Cuatro Banderas ${ }^{12}$. El nombre fue elegido a partir de las distintas adscripciones nacionales de los habitantes: argentinos, bolivianos, peruanos y chilenos. A partir de entonces, las tierras pasaron a ser propiedad de todos los socios, quienes actualmente rondan los 240 .

Para llevar adelante estas gestiones, se conformó una Comisión Directiva o Consejo de Administración integrado por quienes estaban al frente de estas acciones. La mayoría de aquellos primeros dirigentes hoy ya no participan de la entidad, y más aún, hacen explícitas las diferencias con la actual Comisión. Quienes sí han permanecido, ocupan cargos menores y su participación en las reuniones y demás decisiones, es esporádica. En la asamblea que se realizó a principios del año 2009 -después de cinco años de inactividad ${ }^{13}$ fueron confirmados los funcionarios que ya estaban ejerciendo previamente las funciones, por lo que se trató de una instancia formal más que deliberativa.

Describir etnográficamente parte de lo que se debate en las reuniones de la Comisión nos permitirá ver cómo se fundamentan y negocian las clasificaciones que dividen a los vecinos entre cumplidores y deudores. Veremos también cómo la vergüenza, en la acusación ante su falta, opera como un fuerte mecanismo de regulación social que recae sobre determinados morosos. Hacia

estaría demostrando el desarrollo y evolución de los vecinos, y por tanto, de la cooperativa.

11 Si bien esta versión fue la más escuchada, otros entrevistados decían que la idea de organizarse en una cooperativa fue propuesta por los vecinos y no por la empresa. En este sentido, es interesante el lugar que le asignan al peruano Hugo como precursor de dicha iniciativa de acuerdo a su experiencia en su país natal. Según nos dijeron, había sido diputado en Perú y tenía mucho conocimiento sobre cooperativismo, lo cual, junto con ciertas características personales (hablaba bien, tenía labia) convenció a todos de los beneficios de agruparse como tal.

12 Utilizaremos el término cooperativa en letra minúscula para nombrar el espacio social general, en tanto que la mayúscula hará referencia a la entidad.

${ }^{13}$ Según nos relataron, y de acuerdo a lo que pudimos observar, años anteriores no se habían realizado las asambleas anuales para la presentación de los balances económicos porque no había plata para pagar un contador. Por esta razón, la presidenta repetía que casi dan de baja la cooperativa, alertando a los vecinos sobre las consecuencias de la falta de pago. adentro de la Comisión, la 'honestidad', el 'respeto' y la 'bondad' aparecen como atributos inherentes a sus prácticas, en tanto que ponerlos en duda por parte de alguno de los miembros, es motivo de reproches y críticas. Por otro lado, los distintos sentidos de propiedad nos acercan hacia una comprensión más profunda sobre los fundamentos sociales que alimentan las evaluaciones morales, en tanto que las representaciones en torno a las escrituras y el modo de adquirirlas habilitará el análisis en torno a los sentidos que adquieren las prácticas políticas cotidianas entendidas como "continuas operaciones destinadas a capturar espacios de poder" (Boivin et al. 2009:7).

\section{La Comisión: los espacios y las funciones}

La Comisión Directiva o Consejo de Administración está integrado por seis cargos: presidente, secretario, tesorero, dos vocales y un síndico. Estos dos últimos, con sus correspondientes suplentes. Los miembros se reúnen los sábados cada 15 días en casa de Graciela, la presidenta, para atender a los socios, esto es, responder consultas, completar las planillas de seguimiento del pago de los terrenos y de la cuota societaria, redactar alguna nota o discutir algún tema pendiente. Pero lo más interesante es que se trata, y así lo entendemos nosotras, de un espacio en el que se habla y debate una variedad de cuestiones que exceden lo pertinente a sus cargos y que las convierten en vecinas antes que en funcionarias. Dicho de otra manera, estas reuniones son espacios en los cuales se van superponiendo las relaciones de vecinazgo con las actividades propias de las tareas administrativas, y en donde los roles van combinando, nunca de manera clara sino de acuerdo al tema o persona en cuestión.

Generalmente quienes participan de las reuniones son Graciela, Andrea (secretaria), Norma (tesorera), Marisa (vocal) y Raquel (síndica). En el período en el que realizamos nuestro trabajo de campo no presenciamos reuniones en las que participaran los demás funcionarios, como así tampoco escuchamos que alguna vez lo hayan hecho. La casa de la presidenta es el lugar de reunión, cuestión que, entre quienes participan, no generó -al menos ante nosotras- ningún tipo de inconveniente. Por el contrario, sí presentó serias divergencias con los demás miembros. Ernesto, vocal y anterior presidente de la entidad, nos expresó su disconformidad ante el uso de la casa de Graciela, argumentando que para él estas cosas hay que separarlas para que la gente pueda decir lo que piensa. Así, las casas aparecen como espacios que configuran un tipo especial de comportamiento, distinto del que puede otorgar el salón, sitio construido especialmente para este tipo de acontecimientos, pero que no es utilizado para ello ${ }^{14}$.

\footnotetext{
14 El salón fue construido en los primeros años de la cooperativa como un espacio destinado para la realización de distintos acontecimientos de interés común (asambleas, reuniones, celebraciones,
} 
También Miguel, primer presidente de la cooperativa, nos comentó que estaba en desacuerdo con que Graciela lleve todo a su casa puesto que, al igual que Ernesto, creía que tenía que hacerlo en la sede. Nunca llevaría a nadie, a ningún político a mi casa. ¿Me quieren dar leche? Bueno, a la sede, decía. Lili, otra de las primeras habitantes y actual vocal, nos confesaba que no participaba de las reuniones porque no se sentía cómoda en casa de Graciela. Cuando indagamos acerca de esto, nos dijo que las demás mujeres se expresaban de una manera ofensiva, hablando mal de los demás.

La casa de Graciela es, además, el lugar en donde se realizan las asambleas informativas y las reuniones con los políticos ${ }^{15}$, como así también donde se reparten las boletas de luz y agua. En relación a esto último, Graciela y Raquel tuvieron una discusión a propósito de la forma de repartirlas cuando, habiendo acordado previamente hacerlo en casa de ambas, según nos relató Raquel, Graciela cambió de parecer a último momento, disponiendo que se haga todo en su hogar: Yo dije bueno, toda esta parte [de boletas] yo la traía y la daba acá en mi casa y así más fácil (...) y ella agarró y dijo 'no, no, no, no, todas en mi casa'. Ah bueno, tomá, todas en tu casa, hacelo vos.

Cuando le consultamos a Graciela sobre este episodio, nos comentó que el cartero dejaba todo en su casa -ubicada sobre la única calle asfaltada, en el límite con Villa Emancipación- y se negaban a entrar más para el fondo porque la cooperativa era considerada una 'zona roja' de la ciudad. Anteriormente, ella era la encargada de repartirlas casa por casa, o a veces, se distribuían entre los miembros del Consejo para entregarlas cada una a su manzana. Pero luego nos confesó que prefería hacerlo ella sola porque las demás no lo hacían o mandaban a los chicos [hijos] a hacerlo. En otro momento nos comentó que había decidido entregarlas en su casa porque estaba cansada de caminar y porque la gente es vaga, quieren que les den todo servido. En este contexto, podemos comprender que la Cooperativa es la mediadora para que determinados intercambios se puedan llevar a cabo, mediación que puede leerse como un intercambio simbólico de valores donde lo importante reside en mantener un cierto equilibrio vecinal.

Además de los espacios como elemento de disputa,

guardería etc.). Si bien actualmente se utiliza para las asambleas anuales, las mujeres miembros de la Comisión aseguran que este lugar no presenta las condiciones necesarias para realizar allí las reuniones (no tiene techo y el piso es de tierra).

15 Las reuniones con los funcionarios gubernamentales estuvieron enmarcados en dos ámbitos, no siempre delimitados de manera clara, al menos para nosotras. Por un lado, algunas novedades del Programa fueron comunicadas por los propios responsables en reuniones organizadas sobre la vereda de la casa de Graciela; y por el otro, algunos de estos funcionarios también estaban en campaña electoral en vistas a las elecciones legislativas del año 2009, con lo cual eran citados en el mismo lugar para conversar con los vecinos. también la posesión de la boleta, y en este sentido, contar con los datos que ella provee, fue motivo de controversia entre los miembros de la Comisión. Según nos dijo Raquel, Andrea, la secretaria, espiaba los montos de las mismas y advertía a los vecinos acerca de cuánto les había llegado la luz, cuestión que le parecía una falta de respeto. Al respecto dijo:

Raquel: ¡Cómo va a ir ella a decirle cuánto te vino a vos de luz cuando vos vas a pensar que yo, nosotros, le vemos la boleta a todo el mundo! Eso es una falta de respeto porque vos ¿qué vas a pensar? 'iah! estos reparten la luz y te están mirando cuánto tenés que pagar'.

Para Raquel, tomar conocimiento del monto de la boleta y hacer uso de esta información significaba poner en riesgo la honestidad de los miembros que se cristaliza en ese qué van a pensar, cuestión que aparece como fundamental hacia el interior del Consejo. Es interesante pensar la forma en que se ponen en juego las reputaciones en este contexto particular de ser, al mismo tiempo, vecino y funcionario, y el tipo de comportamiento que implica cada uno. Demostrar a través de hechos concretos la 'honestidad' es un punto valioso para las mujeres de la Comisión. Como señala Frederic (2004), la política es entendida muchas veces en términos morales, así como los problemas que de ella devienen en tanto su falta-de, lo cual lleva a que las acciones de los políticos estén siempre sospechadas de ser corruptas y/o clientelares.

Según vemos, la conducta de Andrea es reprochada por Raquel como una práctica que no se corresponde con su función dentro del Consejo, pero no en términos de 'mala vecina'. En esta línea, Bailey (1971) sostiene que la reputación es una cuestión central en contextos de "pequeña política" puesto que, antes que cualidades intrínsecas de las personas, se trata más bien de las opiniones que los demás tienen de ellas. Por ello, el status, en sentido sociológico, significa el conjunto de roles que posee una persona, estableciendo qué acciones y decisiones correspondería que realice estando en determinada posición. Si bien puede poseer múltiples roles, la búsqueda de determinado status es el que permite que sólo algunos puedan ser combinados con otros.

En esta dirección, la molestia aparece además por una incongruencia en tanto que cierta información privada estaba siendo públicamente utilizada. Los ámbitos de lo público y lo privado entran en tensión, cuestión que está presente en muchas otras situaciones dado que las vecinas que forman parte del Consejo tienen también acceso a los datos y registros de cada uno de los socios. Este es otro tipo de conocimiento que ellas manipulan y que nuevamente vuelven vulnerables las fronteras entre una y otra esfera. 
Cuenta Graciela en una reunión: Y no me saluda [hablan de una vecina], paso por la cuadra y le digo yo '¿Usted no me saluda porque debe? Peor para usted', le digo yo. El día... no va a tener la escritura... el día que salgan las escrituras. Así, los escenarios que componen la vida barrial se entrecruzan constantemente generando una serie de tensiones, donde las cuestiones que hacen a las obligaciones hacia la Cooperativa como entidad repercuten en las prácticas vecinales, mostrando la compleja red que tejen y dan forma a las relaciones sociales. En este sentido, es crucial pensar en quiénes están habilitados para ocupar estos cargos y cómo los Ilevan adelante. Detentar un lugar en la Comisión Directiva implica cierto grado de poder para definir públicamente qué uso se debe hacer respecto al dinero. Coincidimos con Puex (2003) en tanto que las relaciones sociales "no se construyen de manera simple o en formas de oposiciones claras, sino que se establecen a través de formas de intercambio y rupturas" (2003:37). Mucho más interesantes se convierten estas disputas cuando pensamos en una cuestión primordial para la vida de la Cooperativa que se vislumbra en el comentario de Graciela, esto es, el pago del terreno.

\section{Pagar o no pagar: la moralidad y la vecindad}

El pago del terreno es una cuestión central para los miembros del Consejo de Administración. La preocupación por que los socios regularicen su situación se ha convertido prácticamente en la función principal de la Comisión. Podríamos decir que, en este ámbito, la reputación de los vecinos fluctúa entre dos polos a partir de su estado económico para con la entidad. Esto es así porque, según ellos, una vez que salgan las escrituras individuales, sólo podrán tener acceso a ellas quienes hayan abonado la totalidad de las cuotas, tanto del terreno como la societaria. En esta dirección, es interesante la forma como son pensados y representados estos deudores por parte de los miembros del Consejo. Graciela, la presidenta, en cada oportunidad que tiene de dirigirse públicamente a los vecinos, aprovecha para recordarles que quienes no paguen el terreno, no van a tener las escrituras, y culmina con un ya me he cansado de decirles. Sostiene, por otro lado, que sólo recibe reclamos o consultas de quienes vienen pagando, puesto que sólo ellos tienen con qué exigirle a la Cooperativa.

Estas manifestaciones públicas en las que muestra su preocupación por el cumplimiento de los pagos, adquiere características particulares cuando en el ámbito de las reuniones de los sábados cada vecino es identificado a partir de un conocimiento de su situación personal y en este sentido, justificando o no la deuda, además de un claro posicionamiento moral sobre su actuación. Decían las vecinas:

Graciela: Agarré y les dije [a una vecina] 'Ustedes son una manga de caraduras porque ustedes no han pagado porque no han querido. Pero no importa porque, pongan verdulería, tengan muchas cosas, y hagan bien bonita la casa para que quede para la cooperativa'. 'No doña Gracielita ya voy pagar' [imita la forma de hablar]. 'No, vos sos una mentirosa y tu marido también porque fue allá al abogado y ¿qué lo que dijeron? Que ya iban a pagar y no pagaron nada. $Y$ no porque no pueda, si una verdulería ya sé lo que da'. Norma: Aparte ellos están... el hombre trabaja de albañil, es contratista.

Graciela: 'Crea usted que ha tenido problemas mi marido con la construcción...'. Y ¿a mí qué me importa?

Norma: Y quién no ha tenido problemas...

La situación económica de estos vecinos parece entrar en contradicción con la falta de pago del terreno, esto es, poner una verdulería junto con el trabajo de albañil estaría demostrando que la deuda surge de una intención explícita de no pagar, y no de una imposibilidad monetaria real. Pero aún éste sea el caso, tampoco estaría justificado para Norma cuando dice "quién no ha tenido problemas", situación que parecería común a muchos y que no alcanzaría para excusarse ante la deuda. Es interesante lo que Pitt-Rivers analiza sobre Grazalema en tanto que

"el dinero es moralmente neutro. Pero los modos en que es adquirido o gastado son temas de enjuiciamiento moral. (...) el dinero es algo que permite a un hombre ser lo que desea ser. Le da poder, poder para ser bueno o malo. Proporciona prestigio sólo si es empleado de una forma moralmente aprobada" (Pitt-Rivers 1994: 93).

En esta dirección, también la casa aparece como elemento que estaría exponiendo un determinado nivel económico en tanto que el ponerla linda implica un manejo de dinero utilizado para adquirir u ostentar algo que se entiende como secundario a la cuota del terreno. Este tipo de uso se desaprueba en tanto que no se corresponde con uno moralmente superior como el saldo del terreno.

Existen también otros elementos que significan, para quienes lo expresan, esta misma contradicción y que por tal, quienes se comportan de esta manera recibe como castigo no merecer consideración alguna ante su morosidad, e incluso, ser calificados de "mentirosos".

En otro momento nos dice Raquel, síndica de la entidad:

Raquel: Nosotros tenemos que ver la dificultad de la gente porque si yo estoy viendo que acá Pérez no pagó nunca el terreno pero él le 
compró una moto a su hijo, tiene las mejores zapatillas de marca, las mejores ropas, los mejores muebles de algarrobo... O sea, no pagan el terreno porque no quieren. ¿Me entendés? (...) Bueno entonces vos no tenés que tener contemplación con esas personas porque estás viendo que no tienen ningún interés. No van a ninguna reunión, no les importa nada.

Tener contemplación con algunos vecinos significa, no sólo una posible rebaja en el precio del terreno o el establecimiento de un acuerdo -arreglo informal que consiste en una serie de cuotas bajas-, sino también una nueva consideración positiva hacia quienes cumplen, de lo cual otros no son merecedores. Pitt-Rivers plantea la "ambigüedad" que supone el dinero como factor que, de acuerdo a su uso específico y al contexto social que lo enmarca, produce valoraciones que pueden variar notablemente. En este sentido, también la ostentación de artefactos, de bienes y de usos, varía y es interpretada de manera distinta según el vecino y según las circunstancias de quién habla y desde qué lugar lo hace. En una oportunidad en que caminábamos junto a Graciela por la cooperativa, ella halagaba las casas 'lindas', valorándolas positivamente en el marco de aquello que aparecía como 'mostrable' del barrio. En aquel momento, las edificaciones de cemento, prolijas y limpias, eran señaladas para que las investigadoras, en tanto personas extrañas, notemos que en Las Cuatro Banderas también hay casas lindas. ${ }^{16}$

Continuando con las representaciones de los vecinos, Graciela se refiere a quienes tienen un acuerdo y no han abonado el terreno: Igual que la Claudia de allá, está embarazada, la sinvergüenza del fondo. Le digo yo: 'estás embarazada... pueda ser que este chiquito venga con el pan bajo el brazo'. Se puso de todos colores... Pitt-Rivers (1994) define la vergüenza como "la capacidad de sonrojarse" que se vincula con lo bueno y lo malo "puesto que su presencia o ausencia es detectada a través de una evaluación ética de la conducta de la persona" (Op. Cit.:139). Es interesante la idea de que los códigos éticos nacen y tienen su fundamento en la "estructura moral de la comunidad", en las sanciones morales que pueden provenir desde el conjunto social del cual forman parte. $Y$ en tanto que

\footnotetext{
16 Zelizer (2011) sostiene que la creciente monetización de la vida social americana entre fines del siglo XIX y principios del XX, no implicó, según se suponía, que el dinero sea tratado como un mediador universal, abstracto e impersonal, sino que, por el contrario, en esas diferentes escenas y contextos, su uso tenía anclaje en dimensiones sociales y morales. Desde su perspectiva, no se puede pensar al dinero como un objeto único, uniforme y generalizable sino que existen "monedas múltiples" que se diferencian socialmente en marcos interaccionales y rituales. Así, la cultura y la estructura social imponen límites a los modos de uso y marcado del dinero. Es posible advertir, siguiendo este razonamiento, que bien pueden tratarse de "monedas" diferentes, pero que para la atenta mirada de las mujeres del Consejo se uniformizan en una utilización condenable.
}

tal, sólo pueden ser penadas aquellas conductas que están a merced de los ojos de los demás, puesto que "hacer algo de modo llamativo convierte a una persona en un sinvergüenza, pero hacerlo de modo discreto le convertiría simplemente en alguien que hace una cosa mala" (Op. Cit:140). Así, la demostración pública de objetos-autos, motos, zapatillas, muebles- o de acciones puntuales -poner linda la casa-, convierte al vecino en un sinvergüenza pues está exponiendo ante la mirada de los demás una conducta que se enfrenta al esquema moral de quienes ocupan los espacios de poder. Sin embargo, entendemos que el conjunto de valores de una comunidad nunca es uniforme, homogéneo y universalmente compartido, sino que corresponde a un proceso complejo en donde los sujetos se enfrentan, obedecen, disputan, o transforman estas normas, pero que nunca les son ajenas.

Retomando el tema del pago del terreno, nos resultó interesante una situación que presenciamos cuando una vecina fue a solicitar una solución pues alegaba que no podía pagar su terreno, aún cuando ella tenía ya un acuerdo:

Vecina: No es de que yo no quiera pagar (...) El tema es de que yo con lo único que estoy es con del plan, que tengo dos nenas, me entran 200 pesos. Estoy sin trabajo, estoy sola con las chicas (...) Yo cuando dije que iba a pagar estaba mi abuela conmigo, o sea, hasta ahí se podía pagar. Vino, se enfermó ella, falleció... yo no tengo otro lado de dónde sacar...

Al respecto, Graciela le respondió:

Mirá, se les daba la posibilidad de que paguen cinco pesos por semana en aquel tiempo, cinco pesos por semana. Yo me cansé de decirle a tu mamá, me cansé. No podía usted, deme la plata, como hice con tanta gente yo, deme la plata, yo voy y le deposito la plata en el banco. No, no querían, bueno...

Si bien en un primer momento no podíamos comprender la actitud inflexible de las mujeres de la Comisión a las que parecía no importarle la situación que esta vecina expresaba, en la segunda parte de lo dicho por Graciela aparece el elemento que establece la diferencia entre ellas y nosotras: formar parte de "la vida comunitaria" en el sentido que Bailey (1971) le otorga, y con ello, su "convivencia estrecha". Las relaciones que se establecen entre los vecinos les permiten hacer estas diferenciaciones entre unos y otros, y así, formular juicios sobre sus comportamientos. En este sentido, la trayectoria familiar de la vecina aparece como un elemento que repercute en las consideraciones que se hacen sobre ella en la actualidad. La madre, según el relato de Graciela, había tenido la oportunidad de pagar 
una determinada cifra y el no querer hacerlo se traslada ahora a su hija atribuyéndole la misma actitud, aun habiendo expresado lo contrario ${ }^{17}$.

Del lado opuesto a los caraduras, están quienes sí reciben una solución o se les tiene contemplación. Así lo expresa Raquel:

Raquel: Yo hace años que estoy, yo sé cómo son las cosas. Entonces dije yo [le dice a un vecino]: 'No, estamos cobrando cuatro mil pesos el terreno pero sabiendo la situación tuya, te lo vamos a dejar más barato. Pero vos no le comentés al vecino y al vecino. Porque yo me entero que vos fuiste y le comentaste a tal persona y viene me reclama a mí, te lo taso a cinco mil pesos ¿eh? Así que calladito la boca'.

Esta posibilidad de rebajar el costo del terreno se convierte así en un acuerdo que se establece en un plano privado, una especie de convenio particular entre el socio y la Comisión que no puede ser compartida con el resto puesto que sería motivo de reclamo. Hacer público este tratado sería romper un pacto que fue establecido en otro ámbito y bajo otras reglas, lo cual tendría su correspondiente castigo: una tasa mayor sobre el terreno.

Es interesante pensar entonces cómo funcionan las consideraciones morales a la hora de otorgar beneficios e impartir castigos dentro de una comunidad, y cómo nuevamente las fronteras entre lo público y lo privado se vuelven fluctuantes y difusas. Como plantea Ana Claudia Marques (2002), las relaciones de vecindad suponen el desarrollo de ayudas mutuas evitando siempre interferir en lo que ocurre "en la casa próxima", en un juego permanente entre la autonomía y la dependencia. Sin embargo, así como la autora trabajó en poblaciones donde las relaciones familiares entraban en juego en la definición de las posiciones sociales, aquí la pertenencia a la Cooperativa supone un nuevo lazo que pone a los vecinos en vinculación constante. $Y$, en este contexto, el intercambio cotidiano en espacios comunes -la calle, el pasaje, las reuniones, la despensa- pero también de información mutua -comentarios, chismes, noticias, "conocerse" en sentido amplio-, vuelve dificultosa la intromisión: "todos los cuidados no impiden, antes bien indican, las interacciones entre vecinos y todo lo que de ellas deriva: complicidad y antagonismo" (2002:52 - La traducción es propia).

Las obligaciones de la Comisión y con ello, las formas en que deberían comportarse vecinos y funcionarios, rondan los discursos y prácticas, y van acomodándose de acuerdo a la situación particular. Al respecto, Balbi

\footnotetext{
17 Pitt-Rivers sostiene que en Grazalema se entendía la vergüenza como una sensibilidad hereditaria: "una persona, hija de padres que no la tienen, mal puede recibirla en herencia" (1989: 140).
}

sostiene que el dinamismo de tales representaciones se fundamenta en que los significados no están 'dados' a los actores sino a través de su experiencia social, con lo cual

\begin{abstract}
"tanto los sentidos de esos conceptos como sus asociaciones emocionales, y hasta su propio contenido moral, no pueden ser entendidos sino como productos contingentes de los procesos sociales que sirven de marco a la sucesión de ocasiones socialmente situadas, a través de las cuales las personas experimentan el mundo circundante" (2007:83).
\end{abstract}

En el siguiente apartado avanzaremos en la reflexión analizando las representaciones que giran en torno a los sentidos de propiedad.

\section{Los dueños y los diversos sentidos de propiedad}

Es habitual escuchar decir a Graciela que la Cooperativa es la dueña de las tierras y que por ello es quien dispone en última instancia sobre las mismas. Esto es, ante el incumplimiento de los pagos, los vecinos podrían ser desalojados. Como vemos, utilizamos la letra mayúscula al hablar de 'la Cooperativa' porque entendemos que está haciendo referencia a la entidad que ella preside y no al conjunto social del que forman parte todos los habitantes. Y esta distinción es fundamental puesto que la presidenta se atribuye el rol de custodiar la tenencia de la tierra y detentar el poder para sacar o no a la gente. Luego de tal advertencia, ella sostenía que no lo habían hecho nunca hasta el momento porque somos demasiado buenas. Pero esta concepción sobre la propiedad de la tierra no es compartida por todos los vecinos, lo cual hace que las representaciones sobre la autoridad y la tenencia de los terrenos se tornen complejas, y muchas veces, contradictorias.

En una ocasión, dialogando con Rubén, uno de los primeros habitantes de la cooperativa, nos comentaba que en las primeras épocas la gente se ayudaba y colaboraba en las tareas de organización del asentamiento, como por ejemplo, rellenar y tapar mallines. Ante nuestra consulta sobre por qué pensaba que eso había cambiado, nos dijo que se debía a que ahora la gente estaba segura porque sabe que de acá no la saca nadie. Es decir, el tiempo de permanencia en el lugar era para Rubén la razón por la cual no sólo se habían perdido ciertos lazos de solidaridad, sino también el motivo que hacía que la escritura no representase para él una preocupación mayor. Ante nuestra indagación, nos relató que no creía que las escrituras fueran a salir y se refirió a que para él no hacen falta.

Estos sentidos que se ponen en juego a la hora de pensar el espacio compartido producen, como decíamos, distintas representaciones que ponen a los vecinos en 
uno u otro lugar. Así, caminando con Graciela una tarde por la cooperativa, pasamos frente a la casa de Rubén y nos comentó: Este Rubén que no paga... Tiene dos terrenos, de él y del hermano, y no paga ninguno. Para los miembros del Consejo de Administración, y más aún para Graciela como presidenta, Rubén es un socio que no cumple con su obligación de pagar el terreno, de manera tal que no podrá acceder a la propiedad del mismo. Las escrituras individuales serían la garantía de esto, cuestión que está sólo en manos de la Cooperativa.

Sin embargo, podemos ver cómo Rubén construye un sistema de significación distinto que lo posiciona como "dueño" de su terreno por fuera de la estructura "legal" que estipula la Cooperativa. Cabe destacar que Rubén formó parte de la Comisión en sus inicios, y se reconoce como uno de los que más hicieron para formar Las Cuatro Banderas. Podemos pensar que esta antigüedad y protagonismo que aduce tener forman parte de un capital interpretado como más importante que lo coloca por fuera de las reglas normativas de la Cooperativa y que posibilita, de alguna manera, agenciar esta actitud desafiante ante la preocupación mayor de la actual Comisión.

Algo similar ocurre con Miguel. Dialogando sobre su llegada a Las Cuatro Banderas, nos comentó que en Argentina existe la posibilidad de tener una o mil hectáreas, cuestión que en su país natal, Bolivia, no existía. Si bien no fue ésta la razón que le adjudicó su llegada al país, sí fue un rasgo que siempre valoró y nombró cuando conversaba con nosotras. Junto con esto, el relato de cómo fueron haciendo la cooperativa fue presentando un sentido de territorio ligado a la acción conjunta, a la propiedad colectiva y al uso comunitario. Miguel nos decía: [las tierras] eran de Minetti, pero nosotros nos juntamos, fuimos y se las compramos. Todos juntos, de todos (...) Yo acá luché, peleé, me agarré a piñas limpias con gentes que han querido vender. En otro momento, y hablando sobre Bolivia, nos contaba que desde el año 1952, y a través de una reforma agraria en su país, la tierra es de quien la trabaja.

Este comentario nos hace pensar en cómo las trayectorias individuales de los sujetos entran en juego a la hora de entender los posicionamientos, y junto con ello, las prácticas que se llevan a cabo. Esta reflexión de Miguel nos abre entonces una nueva puerta para repensar los sentidos que los terrenos adquirían para él. Aquí también la autoridad de la Comisión está puesta en duda en tanto que la escrituración no parece ser el instrumento legítimo sobre el uso y propiedad de la tierra. Por ello, Miguel nos comentó que si bien creía que las escrituras iban a salir, se nombraba a sí mismo como el hacedor de todo esto, en un nivel que también parece diferenciarse del que determinaría dicho documento y que se acerca al expuesto por Rubén.

\section{"Un viejo problema llega a su fin": el Programa}

El 19 de mayo de 2009 el gobierno provincial lanzó formalmente el Programa de Regularización y Escrituración de Viviendas Sociales dirigido a "regularizar la problemática de las viviendas sociales que no han podido ser escrituradas a favor de quienes las habitan"18. Si bien esta fecha se corresponde con su publicación en el boletín oficial, dicho programa fue presentado mucho antes como una voluntad del gobierno por "otorgar una seguridad jurídica a cientos de familias propietarias de viviendas sociales". Cooperativa Las Cuatro Banderas fue incluida dentro de los asentamientos particulares que recibirán la escritura individual, lo cual implicó que tomara visibilidad un proceso de intercambio entre los vecinos y los políticos, y más aún, entre éstos y los miembros de la Comisión Directiva.

El Gobierno de la Provincia de Córdoba enmarcó todo lo referente a dicho programa alrededor de un sentido desde el cual fue articulando su discurso buscando caracterizarlo como el cumplimiento de un deseo anhelado por todos y postergado desde hace mucho tiempo: 'el sueño de la casa propia'. Así, se presenta como quien se hace cargo de estas 'ilusiones' y las lleva a cabo. Para ello, se plantea que existía un problema al cual se le otorga finalmente una solución. Las escrituras significaban tener una titularidad "plena, perfecta y completa" ante una situación de "incertidumbre". Aquí aparece la idea de propiedad definitiva, legítima, muy similar a los sentidos que circulaban dentro de los miembros del Consejo. La escritura significa entonces acceder a una propiedad segura que sólo el gobierno la puede otorgar.

Y así como es importante recibir la llave de la casa propia es también muy importante recibir la escritura de la casa propia, de la casa que uno compró, de la casa que construyó, de la casa que pagó porque cuando se tiene la escritura ahí se tiene en serio la casa y uno se la puede legar a sus hijos [Aplausos]" (Gobernador Juan Schiaretti. Lanzamiento del Programa de Regularización y Escrituración de Viviendas Sociales. Notas de campo, abril 2009).

Junto a ello, se asocian además otros sentidos tales como el aumento del valor de la vivienda, la posibilidad de disponer "libremente" de ella y de heredarla. Por otro lado, se plantea que una vez finalizado este proceso, pasan a formar parte de "un barrio reconocido en los procesos municipales con una situación nominal $y$ definitiva". La idea de culminación de un proceso y el inicio de otro, sostiene la mayoría de los discursos en donde se habla de un nuevo comienzo, de una nueva

\footnotetext{
18 Esta expresión y las que continúan entrecomilladas fueron extraídas del folleto de presentación del Programa entregado a los vecinos.
} 
oportunidad. Graciela expresaba de manera similar que la escritura significará no sólo un nuevo tipo de propiedad, sino también una nueva forma de vida: ser un barrio.

\section{Caminar y conseguir: sobre las formas de hacer política}

Como numerosos estudios han demostrado (Frederic 2004; Goldman y Palmeira 1996; Rosato y Balbi 2003; Quiros 2006; entre otros), para el análisis de los fenómenos socialmente caracterizados como políticos debemos centrarnos en los contextos singulares donde estas manifestaciones tienen lugar, entendiendo que 'lo político' no es un dato a priori sino que debe ser definido a partir de las formulaciones y prácticas de las personas en situaciones particulares. En esta línea, deberíamos observar entonces "cómo los valores morales relacionados a la familia, a las relaciones laborales y de amistad son también fundamentales en la esfera de las actividades políticas" (Kuchnir 2007:26). Una vez que hemos recorrido parte de la vida social de la cooperativa, podemos comprender cómo estos valores y normas se vinculan con las actividades ligadas a 'la política'.

Acceder a las escrituras significa para la presidenta alcanzar un logro que la posicionaría en un lugar de gran visibilidad dentro de la cooperativa, además de un triunfo político llevado a cabo durante su gestión. $Y$ esto es así si tenemos en cuenta los valores que son reconocidos dentro este espacio y cómo se significan las acciones de quien la preside.

Las versiones sobre los protagonismos y logros que describíamos en los apartados anteriores también giran alrededor de aquello que se consigue, es decir, lo que hace o no hace el presidente de la Cooperativa. En este sentido, el servicio de luz y la red de agua son dos de las principales obras que se disputan algunos, haciendo propio el mérito de haberlo alcanzado. Junto a ello, disponer o no de dinero, también repercute en estas conquistas cuando quienes presiden la Cooperativa le otorgan un rol determinante o secundario en su accionar.

Raquel nos relataba que cuando Ernesto era presidente, no podían hacer nada porque no tenían plata, porque para moverte tenés que tener plata y yo no iba a sacar de mi bolsillo para ir a hacerles las cosas acá cuando no te agradecen nada. Como decíamos anteriormente, la Cooperativa no había presentado ante el INACyM los balances anuales durante cinco años, motivo por el cual, en ocasión de la asamblea, el contador explicó que al no haber habido movimiento económico durante ese tiempo, la entidad había estado "prácticamente muerta". Ante esto, Ernesto pidió la palabra y dijo:

No estaba inactiva la Cooperativa, se han hecho muchas... hemos hecho el tema de la luz, ustedes han visto, se ha hecho el tema de la luz.... hemos empujado, se ha hecho también el alumbrado público, se han hecho muchas cosas en la cooperativa, o sea, yo estuve en la Cooperativa (...) Pero... yo quería aclarar eso nada más, como para que no quede que no se ha hecho nada...

Ernesto plantea así un primer sentido de hacer y lo contrapone con el que estaba dictaminando el nulo movimiento económico de los balances. Según el documento leído ante los socios, la Cooperativa mostraba una inactividad que Ernesto niega estableciendo, además, un sentido colectivo a las acciones que, según él, sí se habían realizado. Así, plantea una diferenciación con Raquel en tanto que el dinero no aparece como factor imprescindible para la labor política, sino que pueden existir dos tipos de movimientos -económico y político- y el suyo no dependía del primero. Más aún, haber alcanzado cosas sin pedirle plata a la gente se convierte en motivo de orgullo para aquellos que fundaron la Cooperativa.

Como se ha dicho, dinero y moral parecen pertenecer a esferas separadas, opuestas, a mundos sociales "hostiles" (Zelizer 2011). De acuerdo a su rol de equivalente general, el dinero ha sido conceptualizado en oposición a los lazos morales y afectivos que vinculan a las personas (Wilkis 2008:3-4). Es por ello quizás que quienes presidieron la entidad durante los primeros años, encuentren en el trabajo colectivo y solidario un tipo de compromiso que no lo conseguiría una labor rentada o convertida en un intercambio mercantil. No obstante, como vimos, Raquel -y no sólo ella- sostenía más bien lo contrario. Aún así, es interesante notar que en la queja según la cual 'la plata' fue la razón de la discontinuidad de su trabajo, el hecho de que no te agradezcan nada, aparece como la retribución que ella estaba esperando. Como señalan Carenzo y Wilkis (2009), "lejos de estar asociado naturalmente a un polo de la forma donmercancía, el uso del dinero es un revelador privilegiado de las dinámicas de esta distinción" (2009:161).

Es común escuchar a Graciela hablar en primera persona adjudicándose la labor de caminar, buscar, hacer trámites, hablar con los políticos. Esta forma de presentarse provoca ciertas discrepancias entre los miembros del Consejo, especialmente con Raquel quien dice ser la única que le dice las cosas en la cara a Graciela.

No, no podés decir que vos lo hiciste sola, porque para eso está la Comisión, hay una mesa directiva de la cual somos siete personas. No podés vos ir a todos lados y decir 'porque yo hice poner la luz, porque yo hice poner el agua, porque yo camino por las escrituras, 
porque yo...' Entonces le dije yo, media que me re chifló y le dije a la Graciela: 'si vos hacés todo, ¿entonces qué mierda hacemos nosotros acá?'.

Así como la casa de Graciela como ámbito para realizar las reuniones del Consejo generaba cierta disconformidad entre algunos miembros, algo similar ocurre con el modo como se expresa la presidenta. Raquel se pregunta cuál sería el sentido de la Comisión si en definitiva todo lo haría ella sola. Más aún, niega la posibilidad de una acción personal aduciendo que las cosas fueron hechas por todos.

Este sentido colectivo de las actividades políticas también fue expuesto por Miguel cuando nos relataba las ideas que rondaban el proyecto inicial de la Cooperativa. Comprar más tierras, construir, capitalizarlas, hacer de esto una empresa, eran los modos de contraponer aquellos ideales de antaño al único objetivo que tendría actualmente la Comisión, donde el pago del terreno es el fin exclusivo por el que se trabaja.

Pensar en la Cooperativa significa para los primeros habitantes una constante comparación entre lo que eran los planes de quienes la iniciaron y la actual función. Balbi (1997) analiza "el mito de origen" de una cooperativa de pescadores como relato que reproduce la carga moral que se le atribuyen a ciertos conceptos congelados en el tiempo marcando oposiciones claras. Aquella Cooperativa de la que hablan los vecinos más antiguos también aparece como operando desde un lugar de reserva moral atemporal que les permite reconocerse en ella y distinguirse de la actual Comisión Directiva. Decimos esto pensando en el contexto particular en que, como vimos, el Programa significaría la disolución de la entidad, situación no menor para muchos. Como bien señala Balbi, Malinowski entendía que la función del mito tiene lugar allí donde existe un conflicto sociológico, "y en todos los casos en que han mediado cambios históricos profundos" (Malinowski 1995:52). En términos generales, el mito como tal también es capaz de ofrecer, nos dice el autor, un "modelo retrospectivo" para los valores morales y el orden sociológico (1995:79).

En esta clave de lectura, los núcleos de sentido ligados a las primeras épocas, sus protagonistas y cualidades, dan cuenta también de que el término mismo cooperativa trae consigo una carga moral axiomática en tanto que "se les predica un objetivo que, desde el punto de vista de los asociados, es común a todos ellos y sólo puede ser realizado en base a su unión" (Balbi 1997:104). De allí que sin la existencia de un objetivo "común" -no en virtud de alguna cualidad intrínseca sino de la situación social en que opera la cooperativa-, se hace difícil la perdurabilidad de la agrupación como tal si no se llena de contenido "real" estos conceptos y sus asociados.

\section{Palabras finales}

Coincidimos con Balbi $(1997,2007)$ en tanto que las consideraciones morales deben ser entendidas en términos, fundamentalmente, situacionales. Esto no significa asumir que los juicios de valor no pueden ser anclados en determinados contextos por su condición dinámica y volátil; por el contrario, entendemos que las evaluaciones de carácter normativo son sumamente eficaces en cuanto inciden efectivamente en los comportamientos, al tiempo que son respaldados por sanciones también ellas, eficaces (1997:97).

Como ya se ha dicho aquí, los juicios morales devienen en tanto que tales a partir de una trama de instituciones, relaciones y procesos que, como hemos intentado mostrar, involucran múltiples dimensiones de la vida social. Abordarlos de tal manera nos permite comprenderlos en los contextos donde ellos son formulados, entendiendo que determinadas situaciones pueden mostrarnos cómo a partir de ellos se desplazan o acercan las posiciones entre los sujetos, o para el caso, entre las mujeres de la Comisión y los vecinos.

Como vimos, la cooperativa es un escenario donde las controversias vecinales -con todas sus implicacionesadquieren otro matiz cuando un nuevo vínculo, no menos polémico, enlaza a los vecinos como socios participantes de un proyecto común. Entre los modos de comportarse que demanda cada rol, existen toda una serie de intersticios donde lo justo y lo injusto, lo correcto e incorrecto, es dirimido ponderando uno y relegando otro. Así, el hecho de que la secretaria de la Comisión le anticipe a alguien el monto de la boleta de la luz, puede resultar un gesto de amabilidad por parte de Andrea, pues ella se hacía parte de la extrañeza y preocupación ante la suma inusitada de la misma. Pero como miembro del Consejo, Raquel juzga riesgoso dicho acto puesto que podría ser mal interpretado estas andan espiando-, y entonces, poner en juego el prestigio de su función.

Podríamos decir algo similar respecto a la casa de la presidenta. Como ámbito deliberativo, es probable que la cocina de Graciela no sea vista como apropiada para los integrantes que no asisten a las reuniones. Sin embargo, para las mujeres que sí concurren, es sumamente adecuada como tal, pues la tarea allí se torna placentera, y por ello también fructífera, lo cual les permite hacer su trabajo con gusto. $Y$ de alguna manera, esto hace que concurran con entusiasmo, que sean expeditivas, y que las conversaciones informales o "chismes", no sean elementos corrosivos o disruptivos, sino más bien que formen parte y dinamicen su labor en ese lugar.

Del mismo modo, los usos diferenciales del dinero motorizan evaluaciones divergentes, no sólo porque 
sus significaciones son fundamentalmente sociales, sino también porque lo que está siendo juzgado en este contexto es, además, la actitud de los morosos frente a la función administrativa de la Comisión. El hecho de que gasten $u$ ostenten públicamente sus bienes, no es tan condenable como que no vayan a hablar con ellas, no busquen un arreglo, no aparezcan ningún sábado por la casa de Graciela.

Entre la ayuda mutua y la intromisión inoportuna, la bondad y la no contemplación, una serie de negociaciones moralmente calculadas (Vommaro y Quirós 2011) son cotidianamente operadas por los vecinos, juzgando los comportamientos e intenciones, propios y ajenos. Todas ellas, vale la pena mencionarlo, en el marco de un proceso general singular: a partir del Programa de Escrituración, el pago del terreno cobró otro tenor, principalmente para la presidenta ante los dirigentes a cargo. De algún modo, Graciela se veía comprometida por ellos para que resuelva el tema del pago, lo cual hacía que también ella busque lo mismo frente a sus vecinos.

No obstante, no todos se sentían implicados en esta obligación, sino que más bien el "ser cooperativa" aparece operando como categoría moral que intenta contrarrestar los sentidos hegemónicos y 'legítimos' -de "barrio", de propiedad de la tierra, de hacer política- en un proceso aparentemente definitorio.

Como intentamos mostrar a lo largo del artículo, considerar cómo las mujeres de la Comisión se relacionan con sus vecinos, y cómo a su vez los vecinos se relacionan con estas mujeres, implicó un esfuerzo por intentar comprender las dinámicas bajo las cuales las personas juzgan su mundo social, atendiendo tanto a los intereses, las orientaciones, como los comportamientos. Un ejercicio indagación etnográfica que se parece mucho al que estas personas practican diariamente.

Córdoba, mayo de 2013

\section{Agradecimientos}

Especial mención merecen nuestras compañeras Ana Beltramone, Evelin Muñoz y Raquel Queiroz por la paciente lectura del texto y sus valiosos aportes para corregirlo y enriquecerlo. Gracias a ellas por el cariño con que se dieron a esta tarea.

\section{Bibliografía}

Bailey, F. G. 1971. Gifts and Poison. Gifts and Poison: The Poitics of Reputation. Brasil: Blackwell, Oxford, pp.1-25

Balbi, F. A. 1997. Interdependencia, memoria institucional y valores morales: fundamentos sociales de la moralidad en una cooperativa de pescadores entrerrianos. Avá.
Revista de Antropología Social, Programa de Postgrado en Antropología Social, UNAM, Número 2: pp. 95-111.

Balbi, F. A. 2007. De leales, desleales y traidores. Valor moral y concepción de política en el peronismo. Buenos Aires: Antropofagia.

Bermúdez, N. y Previtali, M. 2013. Merodear la ciudad. Miradas antropológicas sobre espacio urbano e 'inseguridad' en Córdoba. Córdoba: Editorial de la Facultad de Filosofía y Humanidades - UNC (en prensa).

Boivin, M., Heredia, B., Rosato, A. 2010. Política, instituciones y gobierno: abordajes y perspectivas antropológicas sobre el hacer política. Introducción. Buenos Aires: Antropofagia.

Carenzo, S. y Wilkis, A. 2009. Lidiar con dones, lidiar con mercancías. Etnografías de transacciones económicas y morales. Revista Apuntes de Investigación 14: 161-193.

Frederic, S. 2004. El ocaso del "villero" y la profesionalización de los "políticos": sobre el problema moral de la política en el Gran Buenos Aires. Etnografías Contemporáneas, Nro.1, Año 1, pp.: 98-125.

Gravano, A. 2003. Antropología de lo barrial. Estudios sobre producción simbólica de la vida urbana. Buenos Aires: Espacio Editorial.

Kuschnir, K. 2007. Antroplogia da política. Río de Janeiro: Editorial Zahar.

Malinowski, B. 1995. El mito en la psicología primitiva. Estudios de psicología primitiva. Barcelona. Altaya, Grandes Obras del Pensamiento. pp. 17 a 81.

Marques, A. C. 2002. Intrigas e questoes. Vingança de família e tramas sociais no sertão de Perambuco. Rio de Janeiro: Relumen Dumará, Coleçao Antropologia da Política.

Puex, N. 2003. Las formas de violencia en tiempos de crisis. Una villa miseria del conurbano bonaerense. Heridas Urbanas. Violencia delictiva y transformaciones sociales en los noventa. Buenos Aires: Editorial de las Ciencias.

Pitt Rivers, J. 1994. Un pueblo de la sierra: Grazalema. Madrid: Alianza Editorial

Quirós, J. 2006. Cruzando la Sarmiento. Una etnografía sobre piqueteros en la trama social del sur del Gran Buenos Aires. Buenos Aires: Antropofagia

Rosato, A y Balbi, F. A. (Eds.). 2003. Representaciones sociales y procesos políticos. Estudios desde la Antropología Social. Buenos Aires: Centro de Antropología Social, Instituto de Desarrollo Económico y Social \& Editorial Antropofagia. 
Turner, V. 1994. Entre lo uno y lo otro: el período liminar en los "rites de passage". La selva de los símbolos. México: Siglo XXI.

Vommaro, G. y Quirós, J. 2011. 'Usted vino por su propia decisión'. Repensar el clientelismo en clave etnográfica. Desacatos. Nro 36. México. Centro de Investigaciones y Estudios Superiores en Antropología Social. pp: 65-84
Wilkis, A. 2008. Don, dinero y moral en el análisis de un circuito filantrópico. Documentos de Investigación Social. Nro 1. IDAES-UNSAM. Disponible en http://www. idaes.edu.ar/sitio/publicaciones/DoclS_1_ArielWilkis.pdf (Última consulta 20/05/2013)

Zelizer, V. 2011. El significado social del dinero. Buenos Aires: Fondo de Cultura Económica. 